\title{
SUBARACHNOID HEMORRHAGE AFTER ANEURYSM SURGERY
}

\begin{abstract}
CARLOS GILBERTO CARLOTTI JUNIOR*, NELSON MARTELLI* *, JOÃO ALBERTO ASSIRATI JUNIOR*, HÉLIO RUBENS MACHADO***, ANTONIO CARLOS DOS SANTOS****, BENEDICTO OSCAR COLLI***
\end{abstract}

ABSTRACT - The surgical treatment of intracranial aneurysms by clipping is recognized as effective and definitive. However some cases that suffered a new subarachnoid hemorrhage (SAH) some time after they were submitted to aneurysm clipping have raised doubts about the concept of "cure"after this treatment. Eleven patients previously submitted to aneurysm clipping who presented a new SAH were analyzed. The time elapsed from surgery to SAH varied from 3 to 10 years. After SAH four patients had a poor outcome. The new episode of SAH occurred due to intrinsic factors of the cerebral vasculature: 1 . a weak point of the vessel wall near the previous aneurysm, 2. a weak point of another vessel far from the previous aneurysm, 3. a previous infundibular dilation of the posterior communicating artery; and due to technical problems: 1. aneurysm not identified during the previous treatment, 2 . aneurysm deliberately left untreated, 3. persistence of the aneurysm due to inappropriate surgery, 4. persistency of part of the aneurysm neck after clipping and 5. slipping of the clip from the neck of the aneurysm. The measures to prevent new SAH after surgery start with adequate preoperative angiographic studies, a careful inspection of the position of the clip and emptying of the aneurysm. Early angiography studies may reveal a persistent neck and later ones may reveal newly developed aneurysms. In conclusion, SAH after aneurysm clipping is a late and severe phenomenon and the concept of "cure" after this surgery should be interpreted with caution.

KEY-WORDS: recurrent subarachnoid hemorrhage, ruptured cerebral aneurysms, surgical treatment.

Hemorragia subaracnóide após cirurgia de aneurisma

RESUMO - O tratamento cirúrgico dos aneurismas cerebrais através de sua clipagem é reconhecido como eficaz e definitivo. Entretanto alguns casos sofrem nova hemorragia algum tempo após a cirurgia, deixando dúvidas sobre a "cura" pelo tratamento. Onze pacientes submetidos anteriormente a clipagem do aneurisma e que apresentaram nova hemorragia foram analisados. $O$ intervalo de tempo da cirurgia para a nova hemorragia foi de 3 a 10 anos. Após a nova hemorragia, 4 pacientes tiveram evolução desfavorável. $O$ novo episódio de hemorragia subaracnóide ocorreu devido a fatores intrínsicos dos vasos cerebrais ou a problemas técnicos. Dentre os fatores intrinsicos temos: l.um ponto fraco da parede do vaso próximo ao aneurisma, 2 . um ponto fraco em outro vaso longe do aneurisma, 3. dilataçăo infundibular já existente próximo a artéria comunicante posterior. Devido a problemas técnicos encontramos: 1. aneurismas não identificados no tratamento anterior, 2. aneurisma deliberadamente não tratado, 3. persistência do aneurisma por cirurgia inapropriada, 4. persistência de parte do colo do aneurisma após a cirurgia, 5. escorregamento do clip. As medidas para prevenir a nova hemorragia subaracnóide iniciam-se no estudo angiográfico pré-operatório, inspeção cuidadosa da posição do clip e no esvaziamento do aneurisma. A angiografia precoce pode revelar a persistência do colo e a tardia pode revelar o desenvolvimento de novos aneurismas. A hemorragia subaracnóide após a clipagem de aneurisma é um evento tardio e severo, e o conceito de "cura" após a cirurgia deve ser visto com reservas.

PALAVRAS-CHAVE: hemorragia subaracnóide recorrente, aneurisma cerebral roto, tratamento cirúrgico.

Division of Neurosurgery, Department of Surgery and Division of Radiology, Department of Internal Medicine, Hospital das Clínicas, Ribeirão Preto Medical School, University of São Paulo, Ribeiråo Preto, Brazil: *M.D., Assistant Physician (Neurosurgery); **M.D., Assistant Professor (Neurosurgery); *** M.D., Associated Professor (Neurosurgery), ${ }^{* * *}$ M.D., Assistant Professor (Neuroradiology). Paper presented in the 10th European Congress of Neurosurgery (Berlin, May 1995). Aceite: 15-janeiro-1995.

Dr. Carlos Gilberto Carlotti Junior - Departamento de Cirurgia HCFMRP - Campus Universitário USP 14048-900 Ribeirão Preto SP - Brasil. Fax: 016 633-0836. 
The exclusion of intracranial aneurysms by neck clipping is a widely diffuse procedure at all neurosurgery centers and today there is a consensus in the literature that this is the best method for the treatment of this disease ${ }^{2.19}$. However, even after surgery for exclusion of an aneurysm from the circulation in which a patient is considered cured, a new subarachnoid hemorrhage (SAH) may occur, with high morbidity/mortality ${ }^{1,3,9,14,18}$. During the past 10 years we assisted some patients with recurrent SAH after aneuriysm clipping and in this paper we discuss the possible causes of the new hemorrhage and the management to be followed to minimize its risk.

\section{CLINICAL MATERIAL AND METHODS}

From 1984 to 1994, aneurysm surgery was performed in 441 patients in our institution and in this period we assisted 11 patients who presented a new SAH some time after surgery for clipping of a ruptured aneurysm. Five of these were primarily operated on at our institution and 6 elsewhere.

Case Reports (Table 1)

Case I-A 29-year-old white woman, was seen in August 1982 with a history of neck pain of 15 days duration and right ptosis of 6 days duration. Cerebral angiography showed an aneurysm of the internal carotid artery (ICA) - posterior communicating artery (PCoA) (Fig 1A), which was not of the primitive type. Surgery for aneurysm clipping was performed without difficulties. A control angiography showed aneurysm exclusion (Fig 1B) in all incidences. The patient evolved well up to June 1993, when she was examined at our hospital with headache and intermittent right ptosis. A computerized tomography (CT) scan showed hydrocephalus. The patient was submitted to a ventriculo-peritoneal shunt (VPS) and later to cerebral angiography which revealed an aneurysm of the ICA close to the previous clip (Fig IC). The patient was submitted to a further operation and, during surgery, we observed that the microclip initially applied was well positioned, occluding the neck of

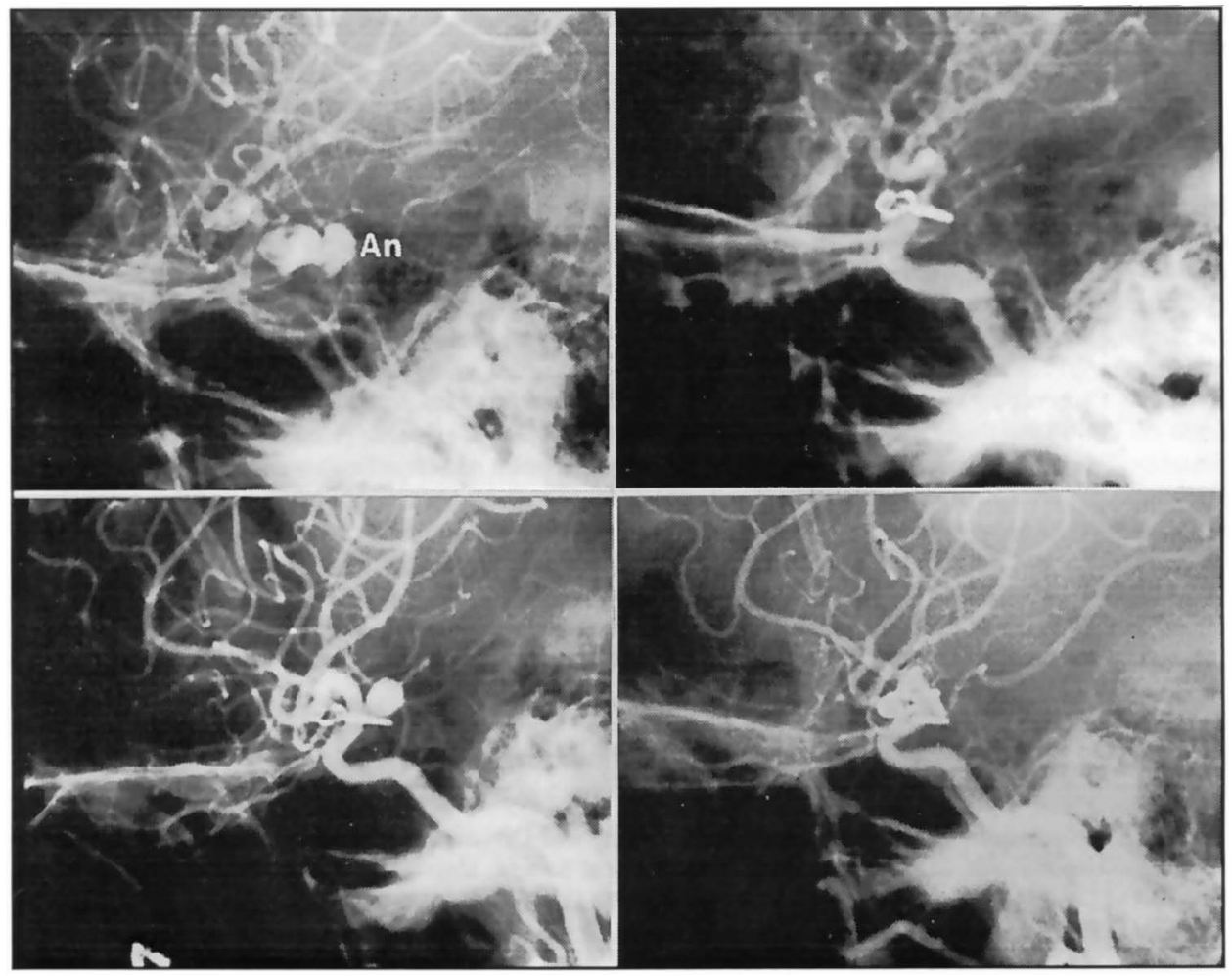

Fig 1. Right carotid lateral angiograms of Case 1. A. Aneurysm (An) of ICA - PCoA.. B. Aneurysm clipped. C. New aneurysm originate near the former (see text) D. New aneurysm clipped. 
Table 1. Summary of patient data and evolution.

Diagnosis and first treatment

Case 1

Clipping of an ICA-PCoA aneurysm.

Normalcontrol angiography.

Case 2

$\mathrm{R}-\mathrm{MCA}$ and $\mathrm{ACOA}$ aneurysms and infundibular dilation (AcoP). Clipped aneurysms, and untreated dilations

Case 3

L-ICA aneurysm operated on in another hospital. R-PCoA, ACoA and basilar artery aneurysms. All clipped. No postoperative angiography.

Case 4

L-MCA, L-ICA, ACoA and R-MCA aneurysms, all clipped except for the R-MCA (Patient declined surgery). Operated on in another hospital

Case 5

Aneurysm of the R-ICA bifurcation. Clipped. Seven years. "De novo"

Case 6

Aneurysm of the L-ICA. Clipped. Postoperative angiography: Proximal L-ICA thrombosis. Operated on in another hospital

Case 7

ACoA aneurysm. Clipped. Megabasilar artery. Operated on in another hospital

\section{Case 8}

L-MCA aneurysm operated on in another hospital.

\section{Case 9}

ACoA aneurysm operated on in another hospital. Non-operated left frontal arteriovenous malformation.

\section{Case 10}

$A C O A$ aneurysm operated on in another hospital.

\section{Case 11}

PCOA and ICA-anterior choroidal artery aneurysms operated on. Basilar artery aneurysm not visualized by angiography. aneurysms of the L-ICA, ACoA and R-anterior choroidal artery.

Time and cause of the new SAH Evolution
Ten years. Neoformed PCoA aneurysm on another surface of the vessel.

Four years. Neoformed PCoA aneurysm.

Four years. Basilar artery aneurysm still showing contrast.

Six years Nonoperated

R-MCA aneurysm.
Return to normal activities. Normal post-operative angiography.

Incapacitated for D L A.
Death

Return to normal activities.

Return to normal activities

Ten years. "De novo"aneurysm of the ACoA.

Incapacited for DLA.

Five years. Aneurysmatic

Death

dilation of the tip of the

basilar artery (unclipped).

Three years. Aneurysm of the tip Return to normal activities. of the basilar artery (undetected? "De novo"?).

Eigth years. Unclipped giant $\mathrm{ACoA}, \mathrm{ACoP}$ aneurysm (undetected? "De novo"?). Left frontal arteriovenous malformation. Cause of SAH was not identified.

Ten years. Unclipped ACoA and MCA aneurysms

Return to normal activities. (undetected? "De novo").

Four years. Unclipped aneurysm Return to normal activities. of the basilar artery (undetected)

"De novo" ACoA aneurysm. 
an aneurysm located in the superolateral angle of the PCoA emergence in the ICA, and another 8-mm aneurysm located in the posteroinferior angle of this junction that was clipped. The postoperative evolution of the patient was good and a control angiography showed exclusion of the second aneurysm (Fig ID). Collagenosis and systemic hypertension was not found.

Case 2 - A 55-year-old white woman, was seen in October 1988 with clinical symptoms of SAH of one week duration. Angiography showed aneurysms of the right middle cerebral artery $(\mathrm{MCA})$ and at the anterior communicating artery $(\mathrm{ACOA})$, as well as infundibular dilation at the ICA-PCoA junction bilateraily. The patient was operated upon for clipping of the two aneurysms. The infundibular dilations were inspected and, despite several attempts, it was impossible to apply a clip in order to reduce them. The patient evolved well up to January 1994 when she was admitted comatose to the hospital. A CT scan revealed a small right temporal hematoma and the angiography an aneurysm at the right ICA-PCoA, where the infundibular dilation had been present previously. The patient was submitted to an external cerebrospinal fluid drainage and later to a VPS. Because of the serious neurological condition of the patient, we decided not to perform surgery. After being discharged from the hospital, the patient improved progressively. In September 1994 she was operated on for clipping of the neoformed aneurysm of the right ICA.

Case 3 - A 34-year-old black woman, was seen in July 1986 after sudden onset of headache 12 days before admission. Discrete hemiparesis on the right and paralysis of the right III cranial nerve was noticed. She had been operated on for intracranial aneurysm clipping at another hospital 6 years before. Carotid angiography revealed an aneurysm of the right ICA-PCOA and another of the ACOA, as well as clips in the topography of the left ICA. The patient was submitted to clipping of the two aneurysms, with a good clinical course. A later angiography of the vertebral-basilar system showed an aneurysm on the tip of the basilar artery. The patient was submitted to aneurysm clipping and emptying by puncture. No postoperative angiographic control was performed. In August 1990 the patient was readmitted to our hospital with a new hemorrhage. A CT scan revealed ventricular dilation and angiography showed filling of the basilar artery aneurysm. The patient was submitted to an external cerebrospinal fluid drainage but she died. Collagenosis and systemic hypertension was not found.

Case 4-A 36-year-old white woman, was operated on in 1985 for multiple aneurysm clipping using a left side approach (left MCA, left ICA and $\mathrm{ACOA}$ ). The patient declined surgery on the contralateral aneurysm (right MCA). The patient did not return and in February 1991 suffered a new SAH. New angiography revealed the aneurysm of the right MCA which was clipped using a homolateral approach. Signs of hemorrhage in the aneurysm region were observed during surgery. The patient had a good clinical course.

Case 5 - A 20-year-old white woman was seen in August 1987 with SAH while in the 6th month of pregnancy. Angiography revealed an aneurysm of the right ICA bifurcation. The patient was operated on, with a good clinical course. In May 1994, she presented a new SAH and a CT scan revealed a localized hemorrhage predominantly in the left basal cisterns. Angiography revealed 3 aneurysms that were not contrasted in the previous angiography, one of the left ICA bifurcation, one of the right anterior choroid artery, and the third of the right PCoA. The patient was submitted to clipping of the 3 aneurysms and presented a good clinical course. Collagenosis and systemic hypertension was not found.

Case 6 - A 31-year-old white man, was seen in April 1984 with a history of headache starting 4 days before, neck stiffness and haemorrhagic cerebrospinal fluid. Angiography showed an aneurysm in the bifurcation of the left ICA, which was clipped using homolateral craniotomy. During the immediate postoperative period, the patient developed right hemiparesis and a control angiography revealed thrombosis of the proximal left ICA, with good filling of the distal left ICA and MCA through collateral circulation by the ACoA from the opposite side. The patient had a good clinical course, with recovery of the motor deficit. In May 1994 he had a new SAH episode and a CT scan revealed hemorrhage in the frontal interhemispheric fissure close to skull base. The patient was admitted comatose to the hospital and improved slightly after an external ventricular drainage. Angiography revealed an aneurysm of the $\mathrm{ACOA}$, thrombosis of the ICA on the left and exclusion of the previously clipped aneurysm. The patient was submitted to clipping of the ACOA aneurysm by reopening of the previous craniotomy and during surgery it was observed that the previous clip was positioned not only in the neck of the aneurysm of the bifurcation, but also involved part of the ICA. The patient did not improve after surgery and continues confined to a bed.

Case 7 - A 35-year-old white man, was seen in August 1989 with a history of sudden headache starting 2 days before. A CT scan showed hemorrhage in the frontobasal interhemispheric fissure, and angiography revealed an aneurysm of the $A C O A$. The patient was submitted to aneurysm clipping and presented clinical signs of vasospasm during the postoperative period, showing progressive recovering. A control angiography revealed persistence of bulging in the $A C o A$ region, although with aneurysm excluded, and an ectatic and elongated basilar artery. The patient was submitted to another operation in an attempt to reposition the clip in 
the aneurysm, but this was not possible because several perforating arteries emerged from the bulging area. The patient had a good course until May 1994, when he suffered a new hemorrhage and was admitted comatose to the hospital. A CT scan showed dilation of the basilar artery, suggesting a giant aneurysm in its bifurcation. The patient died and autopsy revealed intense hemorrhage around the basilar artery. After clot removal it was possible to determine that this artery was ectatic and had an aneurysmic dilation at the tip, with a very thin wall, where

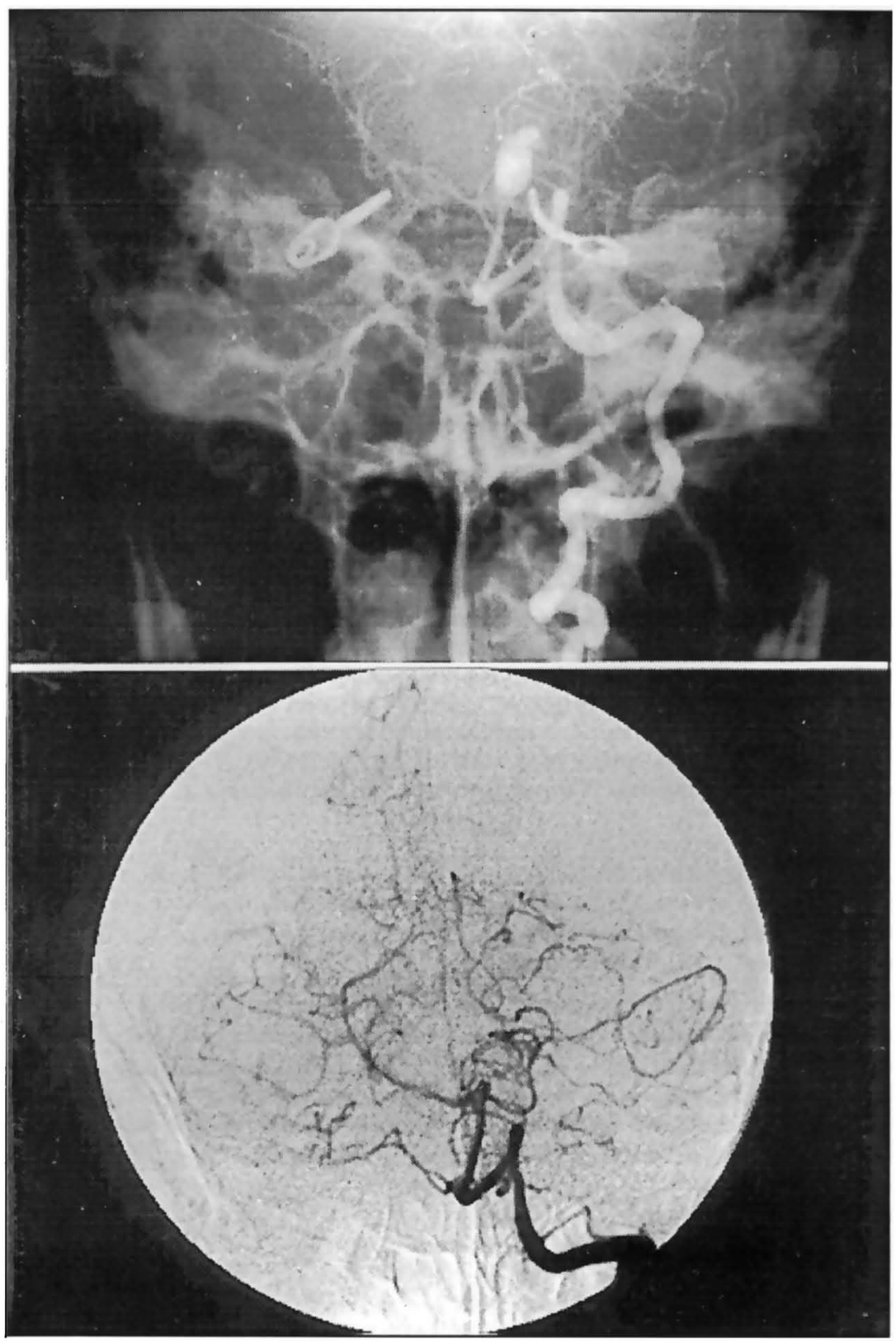

Fig 2. Increasing of aneurysm. A. Angiography done 4 years after the first surgery showing enlargement of the aneurysm. B. A small aneurysm is seen at the basilar tip (Case II). 
the rupture that caused hemorrhage probably occurred. The posterior cerebral arteries emerged from the upper portion of this dilatation, a fact that would have prevented surgical treatment. The carotid arteries also showed several areas of atheromatous plaque and thickened walls.

Case 8 - A 40-year-old white man was seen in May 1994 with a history of a previous operation for aneurysm clipping of the left MCA in another hospital and presenting a new SAH episode starting 2 days before. A CT scan revealed the presence of blood in the cisterns around the brain stem in the posterior fossa, predominantly on the left. Angiography revealed an aneurysm of the basilar artery at the origin of the left superior cerebellar artery. The patient was submitted to surgery and clipping of the basilar artery aneurysm by reopening the previous craniotomy. During surgery it was observed that the previous clip occluded the neck of the MCA aneurysm and involved one of the branches of the MCA bifurcation. The patient had a good postoperative course.

Case 9-A 41-year-old man was seen in June 1993 with SAH and a history of surgery at another service in 1985 for intracranial aneurysm clipping. Angiography revealed clips in the projection of the ACOA and a giant aneurysm of the ACOA, another aneurysm of the rigth $\mathrm{PCOA}$, and an arteriovenous malformation in the left frontal region. At surgery, which was performed using a right pterional approach, we detected a clip occluding the Al branch and two clips in the subarachnoid space. The patient was submitted to aneurysm clipping, with a good clinical course. He refused surgery for the treatment of the arteriovenous malformation.

Case 10 - A 57 year-old-white woman was seen in May 1993 with a history of intracranial aneurysm surgery 10 years before. Angiography revealed an right MCA aneurysm and an ACoA aneurysm, as well as a clip in the ACOA projection. During surgery, the MCA and ACOA (ruptured) aneurysms were clipped. The previously applied clip was positioned in a perforating artery originating from the right $\mathrm{Al}$, outside the neck of the aneurysm. After surgery the patient had a good clinical course.

Case 11 - A 42-year-old white woman was seen on August 9, 1990 with signs and symptoms of SAH. She had a diagnosis of systemic lupus erythematosus. Cerebral angiography revealed bilateral ICA aneurysms (PCoA and anterior choroidal artery). The patient was submitted to left pterional surgery on August 9, 1990 and to right pterional surgery on August 21,1990 , for aneurysm clipping. She was discharged with a normal neurological examination and was well until October 20,1994 , when she was readmitted with new clinical symptoms of SAH and paresis of the left III cranial nerve. A CT scan showed an area of hemorrhage on the left perimesencephalic cistern. Cerebral angiography revealed a $10-\mathrm{mm}$ aneurysm of the basilar tip shifted to the left(Fig $2 \mathrm{~A}$ ) and an aneurysm of the ACOA. The previously clipped aneurysms were excluded from the circulation. Revision of the previous angiography revealed a 3-mm aneurysm at the basilar tip(Fig 2B). The aneurysm of the anterior communicating artery could not be precisely identified. The patient was submitted to reopening of the left pterional craniotomy and clipping of the ACOA aneurysm and of the basilar aneurysm (ruptured), which originated laterally between the left posterior cerebral artery and superior cerebellar artery. During the postoperative period she developed transient paralysis of the III cranial nerve on the left. She was discharged on November 12, 1994.

\section{DISCUSSION}

A surgeon's expectation after clipping an aneurysm and after the risk of vasospasm has decreased is that the patient is cured of his disease. However, the occurrence of SAH during the late postoperative period ${ }^{6}$, with an unfavorable course ${ }^{3,4,9,14}$, has led to a rethinking of this concept and to the proposal of measures that will minimize this risk.

The new SAH episode may occur due to intrinsic factors of the patient's vasculature that permit the formation of a new aneurysm or may be due to technical problems that impair the appropriate exclusion of the aneurysm during clipping ${ }^{2,14}$ or may be to other causes than aneurysm rupture, for example AVM (Case 9). Among the intrinsic factors, we may mention: 1. the formation of a new aneurysm from the pathological segment of the vessel close to the previous aneurysm (Case 1$)^{14} ; 2$. The formation of a new aneurysm from a pathological segment of different location (Cases 3 PCoA, ACoA and basilar; 5, 6, 7, 8, 9- $\mathrm{ACoA}$ and $11-\mathrm{ACoA})^{13}$, and 3. the formation of an aneurysm from a pre-existing infundibular dilation (Case 2) $5,11,17,18,20,21$. Among the technical problems, we may cite the following: 1. presence of an aneurysm that was not identified during the first treatment (Cases 3 - PCoA, ACoA and basilar; 8 - basilar; 9 - ACoA; 10 - MCA; and 11 - basilar); 2. presence of a deliberately unclipped aneurysm (Cases 3-PCoA, ACoA and basilar, 4, 8); 3. persistence of the aneurysm due to inappropriate surgery (Cases $9-\mathrm{ACoA}$; and $10-\mathrm{ACoA}$ ); 4. persistence of the aneurysm neck due to inappropriate clip application (Case 3 - basilar) ${ }^{2.14}$, and 5 . slipping of the clip from its normal position (Case 3 - basilar). 
In the first case, the patient was operated on and control angiography showed complete absence of the aneurysm. However, 11 years later a new aneurysm formed near the clip, indicating that the segment of the artery with a weakened wall extended beyond the origin of the previous aneurysm. In this case there was the formation of a new aneurysm at a site in the PCoA-ICA junction differing from that of the previously treated aneurysm, but in the same area.

In Cases 5,6 and 11 (ACoA aneurysm), we identified "de novo" aneurysms at sites other than the area of the previously treated aneurysm. These patients presented normal angiography in arterial segments that later became pathologic. In the sixth case, the increased flow in the ACoA for the establishment of a collateral network probably contributed to the formation of the new aneurysm, as suggested in the literature ${ }^{15}$.

A situation that we have observed at some frequency in patients operated on for multiple aneurysms is the presence of areas of arterial wall thinning. These areas are mainly located in the bifurcations and have the appearance of a weak point through which blood flow can be seen by transparency through the vessel. These areas may possibly be potential sites of formation of new aneurysms. In these cases we coagulate the lesion when it presents some bulging or we wrap it with muscle or with nylon when it is flat.

The formation of a new aneurysm from an infundibular dilation of the PCoA is a known fact $^{17,18,20,21}$ and has been the subject of a case reported by us previously" ${ }^{11}$. The possibility of the formation of an aneurysm from the infundibular dilation seems to be related to the fact that these lesions present histological alterations in the walls that are similar to those observed in the aneurysms. For this reason, these lesions may be the cause of SAH even without the formation of an aneurysm. A SAH case has been recently reported in which there was infundibular dilatation by angiographic criteria, although surgery identified the origin of bleeding in the dilation, corroborating the impression that these small dilatations should be treated ${ }^{7}$. In Case 2, an infundibular dilation was detected by angiography and during surgery, and later changed into an aneurysm. This patient presented multiple aneurysms, suggesting the presence of generalized vascular disease, as also observed in Case 11 (systemic lupus erythematosus), in which collagenosis may have contributed to the formation of multiple aneurysms.

Whenever possible, infundibular dilations of the PCoA should be submitted to some type of treatment to avoid SAH. In the patients in which they are only an angiographic finding, the most accepted conduct is follow-up with periodic angiographies at 6 month to 1 year intervals. When associated with other aneurysms, they should be explored. Our policy has been to apply a clip to the infundibular dilation parallel to its great axis in order to reduce its volume. This is possible when there is an asymmetrical dilation or when the vessel of origin, generally the PCoA, forms a curve immediately after its emergence, causing an external protrusion. When we cannot achieve this reduction, we eventually wrap the lesion with a muscle or nylon fragment in order to reinforce the vessel wall. However, there is no evidence that these procedures are effective for the prevention of bleeding. Some investigators ${ }^{16}$ recommend wrapping these lesions with plastic substances. The infundibular dilations contralateral to the craniotomy are also explored and treated whenever possible, although they usually are more difficult to clip.

In the third case, two situations occurred. The first was the detection of other aneurysms in a patient operated upon for aneurysm clipping at another service. Due to the lack of precise information, two hypotheses may be considered: 1. lack of identification of the other aneurysms due to an incomplete or technically unsatisfactory angiographic study (that also occurred in Case 11, aneurysm of the basilar artery); 2. formation of new aneurysms, and 3. clipping only of the ruptured aneurysm as a deliberate decision or due to technical difficulties (a fact that also occurred with Patient 8 ). The second situation was observed after the clipping of all aneurysms, including that of the basilar artery, 
in which the possible persistence of a remnant neck even after puncture and emptying, or clip slipping permitted the aneurysm to form again. A late angiographic study might identified this aneurysm before rupture, especially in view of the history of multiple aneurysms and recurrent SAH.

The persistence of a 1-2 mm remnant neck after aneurysm clipping is usually accepted as a low risk situation 4 . However, several cases of SAH have been reported in this situation, suggesting that this concept should be changed. Yasargil ${ }^{19}$ reports that a new aneurysm may originate early (within less than 2 weeks) from the persistent remnant neck after clipping of the previous aneurysm and provoke a new SAH. In our patients and in those reported by others ${ }^{3,4,8,14}$ in whom this situation was observed, the phenomenon occurred late, i.e., several years after the first surgery.

In Cases 9 and 10 we observed an association of technical problems and of intrinsic circulation factors of the patient that may have caused the new hemorrhage: 1 . a new rupture of the inadvertently unclipped initial aneurysm during the first operation (a fact that also occurred in Patient 10); 2. rupture of the associated arteriovenous malformation (AVM), and 3. rupture of the new aneurysm formed at another site, favored by the high AVM flow.

With respect to aneurysms of the anterior circulation, there is a predominance of recurrence or formation of a new aneurysm when the previous one was in the ICA-PCoA, especially when the PCoA is of the primitive type ${ }^{14}$. In addition to the greater flow and stress in this region ${ }^{15}$, when aneurysms are located in the posteromedial region of the ICA-PCoA junction, the visualization of their necks is difficult. This can lead to incomplete clipping which may not be identified by the surgeon even after aneurysm puncture and emptying.

Case 4 reinforces the concept that an unruptured aneurysm should be approached surgically, especially in young patients ${ }^{12}$. In the present case, the new SAH due to postponement of surgery fortunately did not provoke an unfavorable outcome.

In Case 7 the patient presented diffuse arterial disease probably due to a metabolic alteration, with the formation of atheromatous plaque and dilation of the basilar artery. Even after visualizing the artery at autopsy we were unable to imagine an efficient treatment for this alteration.

The measures to be taken to avoid SAH recurrence in patients submitted to aneurysm clipping should start before the surgery. Angiographic study of the four cerebral vessels is imperative, regardless of the finding of an aneurysm in the anterior circulation. The technical quality of the examination should be adequate to permit the visualization of small lesions, including incidences in oblique positions whenever necessary.

A careful inspection of the positioning of the clip in relation to the neck of the aneurysm should be made during the surgery in an attempt to eliminate the persistence of an unoccluded portion of the neck. However, the major problem is the persistence of a segment of the aneurysm not excluded by the clip. Aneurysm puncture and emptying is a very important procedure to minimize this problem since it permits a better mobilization of the aneurysm and of the vessel and a better visualization of the anatomical relationships. Another maneuver that can be used is the visualization of aneurysms located posteriorly to the vessel of origin, as is the case for some aneurysms of the ICA-PCoA junction, using small mirrors or endoscopes. The first maneuver to be considered for the elimination of neck or aneurysms remnants is clip repositioning. When the aneurysm is ruptured this maneuver may be performed using a new clip applied distally to the first or, when this is not possible, temporary clipping of proximal and distal vessels may be used. When clip repositioning does not solve the problem, the clip should be replaced by another of more appropriate shape, or a second clip may be applied to the persisting neck segment. Fenestrated clips with different angulations applied with the blades placed posteriorly and parallel to the carotid and with the fenestra surrounding the vessel, are very useful to avoid the persistence of neck segments in the medial portion of the aneurysm, especially in some aneurysms of the ICA-PCoA junction. 
A control angiography performed after surgery may be another auxiliary measure in the identification of neck segments or of persisting aneurysms, in addition to permitting visualization of inadequate clip positioning in relation to the normal vessels ${ }^{10}$. However, angiographies performed during the first postoperative days may not reveal a $1-2 \mathrm{~mm}$ neck remnant, which may be masked by the clip blade $^{3}$. For this reason, some authors ${ }^{14}$ proposes a late control angiography for all patients submitted to ICA-PCoA aneurysm clipping, especially when the PCoA is primitive and the patient is young.

We have routinely performed aneurysm puncture and/or emptying and more recently we have resected and coagulated the aneurysm segment distal to the clip. We believe that early or late control angiography can identify alterations that may cause new hemorrhages. However, due to the difficulties encountered at our hospital, we have not performed these procedures in a routine manner. Early angiographies are performed only in patients in whom some technical problem occurred during clipping and late angiographies are performed for patients with evidence of difuse vascular illness (multiple aneurysm and or weak points in the vascular wall seen during surgery).

In conclusion, the classical concept of "cure" after aneurysm clipping should be viewed with caution or even replaced with "probable cure", because SAH may recur several years after the first surgery. This can occur whem the patient has already been discharged from the outpatient clinic, causing embarrassment for the physician, since recurrent SAH is a very serious phenomenon, as observed in four of our cases (two deaths and two patients confined to bed).

\section{REFERENCES}

1. Drake CG, Vanderlinger RG. The late consequences of incomplete surgical treatment of cerebral aneurysms. J Neurosurg 1967;27:226-238.

2. Drake CG. Friedinan AH, Peerless SJ. Failed aneurysm surgery: reoperation in 115 cases. J Neurosurg 1984;61:848-856.

3. Ebina K, Suzuki M, Andoh A, Saitoh K, Iwabuchi T. Recurrence of cerebral aneurysm after initial neck clipping. Neurosurgery 1982;11:764-768.

4. Feuerberg I, Lindquist $C$, Lindqvist M, Steiner L. Natural history of postoperative aneurysm rests. J Neurosurg $1987 ; 66: 30-34$

5. Hassler $O$, Saltzman GF. Histologic changes in infundibular widening of the posterior communicating artery: a preliminary report. Acta Pathol Microbiol Scand 1959;46:305-312.

6. Kamitani H, Masuzawa H, Kanazawa 1, Kubo T, Tokuyama Y. A long tem follow-up study in direct cerebral aneurysm surgery. Acta Neurochir (Wien) 1995;133:134-140.

7. Koike $G$, Seguchi K, Kyoshima K, Kobayashi S. Subarachnoid hemorrhage due to rupture of infundibular dilatation of a circumflex branch of the posterior cerebral artery: case report. Neurosurgery 1994;34:1075-1077.

8. Lin T, Fox A, Drake CG. Regrowth of aneurysm sacs from residual neck following aneurysm clipping. I Neurosug 1989;70:556-560.

9. Little JR, Awad IA. Intracranial aneurysm. In Little JR, Awad IA (eds.)I: Reoperative neurosurgery. Williams \& Wilkins, 1992:209-218.

10. Macdonald RL, Mallace C, Kestle JRW. Role of angigraphy following aneurysm surgery. J Neurosug 1993;79:826-832.

11. Martelli N, Colli BO, Assirati JA Jr., Machado HR, Moriol AR. Aumento de tamanho de pequeno aneurisma documentado por angiografia e autópsia. Arq Bras Neurocinurg 1983;2:133-138.

12. Moyes PD. Surgical treatment of multiple aneurysms and of incidentally discovery unruptured aneurysms. $J$ Neurosurg 1971;35:291-295.

13. Rimne J, Hemesniemi. De novo aneurysms: special multiple intracranial aneurysms. Neurosurgery 1993;33:981-985.

14. Sakaki $T$, Takeshima T, Tominaga $M$, Hashimoto $H$, Kawaguchi $S$. Recurrence of ICA-PCoA aneurysms after neck clipping. INeurosurg 1994;80:58-63.

15. Stehbens W. Etiology of intracranial aneurysms. J Neurosury 1989;70;823-831.

16. Stroobandt $G$, Cornelis $G$, Thauvoy $C H$. Les anévrysmes sacculaires multiples du système carotidien supraclinoidien. étude anatomo-clinique et therapeutique. Neuro Chirurgie 1973;19(Suppl 1):1-96.

17. Stuntz JT, Ojemann GA, Alvord CC Jr. Radiographic and histologic demonstration of an aneurysm developing on the infundibulum of the posterior communicating artery: case report. J Neurosurg 1979;35:591-595.

18. Waga S, Morikawa A. Aneurysms developing in the infundibular widening of the posterior communicating artery. Surg Neurol 1979;11:125-127

19. Yasargil MG. Microneurosurgery: clinical considerations, surgery of the intracranial aneurysms and results. Stuttgart:: Georg Thieme Verlag, 1984, Vol 2.

20. Yoshida M, Anegawa S, Moritaka A. Significance of infundibular dilatation in unexplained subarachnoid hemorrhage. Neurosurgery 1981;9:718-721.

21. Yoshimoto T, Suzuki J. Eight year demonstrated study of an aneurysm growth at the origin of the posterior communicating artery. Neurol Med Chir (Tokyo) 1974;5:571-573. 